\title{
Digestive and Cardiovascular Responses to Core and Animal-Reminder Disgust.
}

Citation for published version (APA):

van Overveld, M., de Jong, P. J., \& Peters, M. L. (2009). Digestive and Cardiovascular Responses to Core and Animal-Reminder Disgust. Biological Psychology, 80, 149-157.

https://doi.org/10.1016/j.biopsycho.2008.08.002

Document status and date:

Published: 01/01/2009

DOI:

10.1016/j.biopsycho.2008.08.002

Document Version:

Publisher's PDF, also known as Version of record

\section{Document license:}

Taverne

\section{Please check the document version of this publication:}

- A submitted manuscript is the version of the article upon submission and before peer-review. There can be important differences between the submitted version and the official published version of record.

People interested in the research are advised to contact the author for the final version of the publication, or visit the DOI to the publisher's website.

- The final author version and the galley proof are versions of the publication after peer review.

- The final published version features the final layout of the paper including the volume, issue and page numbers.

Link to publication

\footnotetext{
General rights rights.

- You may freely distribute the URL identifying the publication in the public portal. please follow below link for the End User Agreement:

www.umlib.nl/taverne-license

Take down policy

If you believe that this document breaches copyright please contact us at:

repository@maastrichtuniversity.nl

providing details and we will investigate your claim.
}

Copyright and moral rights for the publications made accessible in the public portal are retained by the authors and/or other copyright owners and it is a condition of accessing publications that users recognise and abide by the legal requirements associated with these

- Users may download and print one copy of any publication from the public portal for the purpose of private study or research.

- You may not further distribute the material or use it for any profit-making activity or commercial gain

If the publication is distributed under the terms of Article $25 \mathrm{fa}$ of the Dutch Copyright Act, indicated by the "Taverne" license above, 


\title{
Digestive and cardiovascular responses to core and animal-reminder disgust
}

\author{
W.J.M. van Overveld ${ }^{\mathrm{a}, *}$, Peter J. de Jong ${ }^{\mathrm{b}, * *}$, Madelon L. Peters ${ }^{\mathrm{a}}$ \\ ${ }^{a}$ Department of Clinical Psychological Science, Maastricht University, P.O. Box 616, 6200 MD Maastricht, The Netherlands \\ ${ }^{\mathrm{b}}$ Department of Clinical and Developmental Psychology, University of Groningen, Grote Kruisstraat 2/1, 9712 TS Groningen, The Netherlands
}

\section{A R T I C L E I N F O}

\section{Article history:}

Received 8 June 2007

Accepted 7 August 2008

Available online 14 August 2008

\section{Keywords:}

Disgust

Blood Phobia

Psychophysiology

\begin{abstract}
A B S T R A C T
The two-stage model of disgust differentiates between core and animal-reminder (AR) disgust [Rozin P., Fallon A., 1987. A perspective on disgust. Psychological Review 94, 23-41]. This study investigates whether core and A-R disgust elicit distinct physiological reaction patterns. Further, in line with the idea that A-R disgust is critically involved in blood phobia and may explain typical phenomenology of psychopathological symptoms (e.g., dizziness), we investigated whether physiological patterns (if present) would differ specifically for A-R disgust between high and low blood-fearful participants. Therefore, high $(n=30)$ and low $(n=30)$ blood-fearful individuals engaged in guided imagery of core disgust, A-R disgust, and neutral stimuli. Overall, both disgust scripts lead to increased activity in the digestive component of the autonomic nervous system (ANS). For cardiac components, sympathetic activity decreased, whereas no parasympathetic reactivity was observed compared to the neutral script. No differences were observed in physiological reactivity between the A-R and core disgust scripts. Meanwhile, in line with the idea that disgust is involved in blood phobia, subjective symptoms of vomit and dizziness did differentiate between high and low blood-fearful participants, as subjective symptoms were most pronounced in the high blood-fearful group. Contrary to our expectations, increases in subjective symptoms were apparent for both disgust types and not specifically for A-R disgust. So, physiological reactivity appeared relatively independent of type of disgust elicitor which, in turn, may reflect a general hard-wired protective mechanism to prevent contamination with pathogens.
\end{abstract}

(C) 2008 Elsevier B.V. All rights reserved.
From an evolutionary perspective, disgust is seen as a defensive mechanism protecting the organism from contamination by pathogens (Rozin and Fallon, 1987). Accordingly, disgust is focused on the intersection between the body and the environment and concentrates on the skin and body apertures (Rozin et al., 1995; Fessler and Haley, 2006). The strength of the disgust response increases as a function of proximity of the potential contaminant and the sense of inclusion. Thus, the closer the stimulus and/or the more intense the physical contact, the stronger is the disgust response. Core disgust is exemplified by food-rejection responses, reactions that occur at the threat of consuming a disgusting stimulus (Rozin and Fallon, 1987; Power and Dalgleish, 1997).

In his two-stage model of disgust, Rozin and colleagues argued that the defensive mechanism of disgust originally evolved to prevent the body from contamination by pathogens and toxins from the outside environment (core disgust) is extended to stimuli

\footnotetext{
* Corresponding author. Tel.: +31 43 3881608; fax: +31 433884155 .

** Corresponding author. Tel.: +31 503636403 .

E-mail addresses: M.vanOverveld@DMKEP.Unimaas.nl (W.J.M. van Overveld), P.J.de.Jong@rug.nl (P.J. de Jong).
}

and/or behaviors that remind us of our animal nature (Rozin et al., 1999a). Accordingly, people are not only disgusted at the prospect of having to consume something disgusting, they also tend to be disgusted by stimuli that emphasize the similarities between humans and animals. This reminder that people are of animal origin is a thought that most people consider unacceptable (Rozin et al., 1999a), presumably because humans wish to rise above the animal kingdom, and not be reminded that they too are mortal creatures of flesh and blood. Therefore, disgust for these stimuli is labeled animal-reminder disgust (A-R; Haidt et al., 1994).

Consistent with the two-stage disgust model of Rozin et al. (1999a), factor analytical studies have shown that core disgust and animal-reminder disgust elicitors can be systematically distinguished as separate constructs (Olatunji et al., 2007). Moreover, there is accumulating evidence that disgust is involved in various psychopathological complaints (Olatunji and McKay, 2007). Adding to the validity to differentiate between A-R and core disgust, a series of studies provided evidence that A-R and core disgust are differentially involved in these various types of psychopathological symptoms. For example, fear of spiders is typically associated with heightened levels of core disgust propensity (i.e., tendency to experience core disgust more rapidly), 
whereas fear of blood-injury stimuli has been found to be specifically associated with a heightened disgust propensity for A-R stimuli (de Jong and Merckelbach, 1998). More recently, Sawchuk et al. (2000) corroborated these earlier findings showing that blood-injection phobics displayed a stronger disgust propensity for A-R stimuli than spider phobics or non-phobics, whereas no such difference was evident for core disgust stimuli.

The major aim of the present study was to establish whether core and animal-reminder disgust may not only vary in their reference to different classes of disgust elicitors, but perhaps also in their concomitant response patterns of the autonomic nervous system (ANS). If so, this would not only further substantiate the validity of distinguishing between different types of disgust, it may also help explaining the typical phenomenology of psychopathological symptoms that are related to each of these types of disgust.

For example, blood phobia is typically characterized by dizziness and feeling faint (Page, 1994), whereas these symptoms are usually absent in other disorders in which disgust is also assumed to be critically involved such as spider phobia. One explanation might be that specifically confrontation with A-R disgust stimuli (e.g., blood) results in a sympathetic withdrawal and/or parasympathetic activation of cardiovascular components of the ANS resulting in a drop in blood pressure which, in turn, may give rise to feelings of dizziness. Indeed, blood and injection stimuli have been found to lead to the so called diphasic response (i.e., initial increase in sympathetic nervous system (SNS) activity, followed by a sudden and possibly parasympathetically mediated drop below baseline levels). Most importantly, this response was most pronounced in blood-fearful persons with relatively high levels of disgust propensity (Page, 2003).

Since core disgust originates from a withdrawal response regarding the oral incorporation of potential contaminants (Rozin et al., 1999a,b), it would make sense that core disgust typically activates digestive rather than cardiovascular components of the ANS (e.g., saliva production, tendency to vomit). This may explain why feelings of dizziness are generally absent in psychopathological symptoms in which core disgust rather than A-R disgust is assumed to be critically involved (e.g., spider phobia; de Jong and Merckelbach, 1998). Germane to the alleged role of the digestive nervous system in food aversion responses, it has been shown that consuming aversive bitter tasting foods increases saliva production (Norris et al., 1984). Such increased saliva production is closely associated with a gaping response or vomiting (Hornby, 2001) and is thus likely to be the result of experienced disgust or nausea.

We decided to use guided imagery, because it might well be that using emotionally more intense movie clips or behavioral experiments may elicit 'fight/flight'-responses that interfere with the generation of straightforward disgust responses. That is, the 'fight/flight'-response is associated with an increase in sympathetic and parallel decrease in parasympathetic reactivity (Barron and van Loon, 1989; McDougall et al., 2005). It has been proposed that disgust is associated mainly with parasympathetic activity (Levenson, 1992). Since increases in sympathetic activity are generally associated with fear and anxiety, it is reasonable to assume that emotionally intense stimuli that evoke stronger sympathetic activity will reduce the sensitivity of the procedure to detect genuine disgust-induced (para)sympathetic response patterns. Imagination procedures seem less susceptible to such undesirable influences as participants remain in control over their emotional regulation, yet, they are nevertheless effective in evoking emotions (Lang, 1979; Prkachin et al., 1999; Vrana, 1993). Moreover, confrontation with a stressor may activate particularly sympathetically mediated activity in the cardiovascular system (Barron and van Loon, 1989). Since we were interested in parasympathetic influences on the cardiovascular system, imagery was chosen as it may limit the effects of sympathetically mediated activity on this system.

To examine whether distinct disgust types evoke separate physiological response patterns, the study focused on core and A-R disgust elicitors. Core disgust imagery was hypothesized to induce activity of the digestive component of the ANS (increase in saliva production), whereas A-R disgust imagery was hypothesized to elicit reactivity of the vascular component (characterized by SNS withdrawal and PNS activation as indexed by increased T-wave amplitude, increased activity in the high frequency power band of heart rate variability, and a decrease in mean arterial pressure).

Further, given the predominant role of disgust in blood phobia (e.g., Page, 1994), we tested whether blood-fearful participants and non-blood-fearful participants would differ in their subjective and physiological responding to core and A-R disgust elicitors. On the basis of previous findings that blood-fearful individuals typically display inflated levels of A-R disgust propensity (e.g., de Jong and Merckelbach, 1998), we anticipated that high blood-fearful individuals would report more intense feelings of disgust and heightened physiological reactivity in response to A-R imagery than to core imagery compared to low blood-fearful individuals (in particular, increased T-wave amplitude, increased activity in the high frequency power band of heart rate variability, and a decrease in mean arterial pressure). There are only a few studies in the literature that examined the peripheral physiological reactivity toward disgusting stimuli, and all of these studies used bloodrelated stimuli such as cardiac surgery clips (e.g., Palomba et al., 2000). It is therefore difficult to decide on the basis of these earlier findings whether these responses are specific for blood-related stimuli or are also representative for A-R disgust or disgust in general. Especially, since blood-fearful individuals report to experience both fear and disgust for blood stimuli (e.g., Lumley and Melamed, 1992; Tolin et al., 1997; Ritz et al., 2005). Therefore, an A-R script was used without references to blood stimuli to avoid confounding by fear-induced physiological reactivity. Reactivity during core disgust imagery was assumed to be similar for both groups (in particular, increased production of saliva and increased activity in the $\mathrm{m}$. levator).

\section{Methods}

\subsection{Participants}

The participants were students at Maastricht University, from the faculties of Health Sciences, Medicine, and Psychology. The participants were recruited via posters, and advertisements in the university buildings and asked to complete the blood subscale of the medical fear survey (MFS; Kleinknecht et al., 1996). From a total of 246 respondents, the 30 lowest and 30 highest blood-fearful individuals were invited to participate in the present experiment. Since most of the students at these faculties are women, the research population also consists predominantly of women $(86.7 \%)$. The mean age was 22.9 years $($ S.D. $=6.86)$. Participants were assigned to the high blood-fearful group, if two of the following criteria were met: (a) they rated themselves at least 7 on a scale from 1 (=not blood fearful at all) to 10 (=extremely blood fearful), (b) MFS-blood $>5$, and (c) blood-injury phobia questionnaire-fear subscale (BIQ-fear; de Jong and Merckelbach, 1998) $>20$. Participants were assigned to the low blood-fearful group, if they (a) rated themselves non-blood fearful ( $<5$ ), (b) MFS-blood $<5$, and (c) BIQ-fear $<18$. Of the blood-fearful group, $90 \%$ were women ( 27 women and 3 men) whereas in the low blood-fearful group, $83 \%$ were women ( 25 women and 5 men).

\subsection{Materials}

1.2.1. Questionnaires on fear of blood

1.2.1.1. Multidimensional blood/injury phobia inventory (MBPI; Wenzel and Holt, 2003). This questionnaire was devised to measure the full range of phobic fears in blood phobia. The MBPI assesses four types of stimuli (injections, injury, hospitals, blood) and five types of responses (fear, avoidance, worry, fainting and disgust), and a self versus other focus. It consists of 40 items on a five-point scale ( $0=$ very slightly or not at all; $4=$ extremely). Based on factor analysis, six subscales have been identified in the MBPI: injections, hospitals, fainting, blood-self, injury and bloodinjury-others (Wenzel and Holt, 2003). Internal consistency is good (Cronbach's alpha $=.91)$. 
1.2.1.2. Medical fear survey (MFS; Kleinknecht et al., 1996). This questionnaire assesses fear of medical stimuli using five 10-item subscales (mutilation, sharp objects, examinations and symptoms as intimation of illness, injections and blood draws, blood). Participants rate whether a series of statements are typical of them on a scale from 0 (=very slightly) to 4 (=extremely). The subscales are reliable ( $\alpha=.84-.94$, Kleinknecht et al., 1999; .87-.97, present study).

1.2.1.3. Blood-injury phobia questionnaire (BIQ). This is a 20 -item questionnaire on which participants rate their fear of blood-injury items on a five-point Likert scale from 1 ('no fear') to 5 ('extreme fear'). The first ten items are derived from the fear questionnaire (Marks and Mathews, 1979) and the fear survey schedule (Wolpe and Lang, 1964). The second part of the BIQ assesses if participants have fainted in the presence of the stimuli which were mentioned in the first 10 items. Participants have to rate if they have fainted on a scale from 1 (=never) to 3 (=often). The internal consistency of the BIQ is good (.84; Merckelbach et al., 1999).

\subsubsection{Disgust questionnaires}

1.2.2.1. Disgust scale (DS; Haidt et al., 1994). The disgust scale measures disgust propensity across a broad domain of disgust elicitors. The 32 items can be divided into two parts. The first part of the DS has only true/false type questions on which the person has to fill in if they agree to a series of statements, the second part consists of $0-2$ ratings of how disgusting specific experiences would be to them While Cronbach's alpha for the total score is high (.84; Haidt et al., 1994), internal consistency for the original eight subscales is low (alphas ranging between .34 and .64; Haidt et al., 1994). Therefore, the present study will use the two subscales that were recently recommended measuring only core disgust and A-R disgust (Olatunji et al., 2006).

1.2.2.2. The disgust and contamination sensitivity questionnaire (DQ; Rozin et al., 1984). This 24-item questionnaire measures disgust propensity for core disgust. On a scale from 1 to $9(1=$ not at all, $9=$ very much $)$ participants have to rate how much they would like to eat a certain food item, after it has been contaminated with a specific item. A total score can be calculated (range 24-216) with an inverse scoring format, so higher scores reflect lower levels of disgust propensity. The DQ appears a reliable instrument (Cronbach's alpha $=80$; Mulkens et al., 1996; .84 Merckelbach et al., 1993). Internal consistency ranges from .72 to .86 (Davey, 1994)

1.2.2.3. Disgust propensity and sensitivity scale-revised (DPSS-R; van Overveld et al. 2006). The DPSS-R is a measure of disgust propensity (i.e., the tendency to experience disgust more readily), and disgust sensitivity (i.e., how negatively does the individual evaluate the disgust experience). It measures these constructs irrespective of specific disgust elicitors. Participants have to rate on 16 items their agreement with a series of positions on how often they experience certain bodily symptoms on a scale from 1 (='never') to 5 (=‘always'; range: 32-160) (e.g., 'When notice that I feel nauseous, I worry about vomiting'). A recent validation indicates that the DPSS-R is a valid and reliable instrument (alpha's for both subscales $>.71$; van Overveld et al., 2006).

\subsubsection{Apparatus}

1.2.3.1. Saliva production. The production of saliva was used as an index of parasympathetic activity related to the digestive system (Proctor and Carpenter, 2007) and was measured using dental cotton rolls. One roll was placed sublingually and two rolls buccally, which is known as the Strongin, Hinsie \& Peck (SHP) technique (White and Sher, 1977). The cotton rolls were inserted prior to the start of each script and replaced immediately after the presentation of each imagination script. The weight of the rolls was then determined before and directly after presentation of the imagination scripts. This method has been shown to be valid and reliable (Nederkoorn et al., 1999).

1.2.3.2. Facial electromyography (EMG). As a physiological index of disgust, facial EMG at the levator labii and $\mathrm{m}$. corrugator supercilii were recorded. The levator muscle was selected because previous studies indicated that relative to other negative emotions, levator activity is specific to disgust (e.g., Vrana, 1993). The corrugator was selected because it was found to increase during negative emotions in general. Hereto, two pairs of $\mathrm{Ag} / \mathrm{AgCl}$ Beckman electrodes with a diameter of $.25 \mathrm{~cm}$ and filled with Spectra 360 electrode gel were attached to the left side of the face, in accordance with recommendations by Fridlund and Cacioppo (1986).

1.2.3.3. Electrocardiogram (ECG). The ECG-signals were recorded using pre-gelled single-use disposable $\mathrm{Ag} / \mathrm{AgCl}$ ECG surface electrodes (Ambu Bluesensor) with a diameter of $.55 \mathrm{~cm}$. Electrodes were placed on the participant's chest, two attached to the left lower ribs, and one electrode on the participant's sternum. Three unipolar leads connected the electrodes directly with a Picker/Schwarzer Coupler (ED 14/ 12). Heart rhythm was continuously monitored and the data was stored on the lab server. From the ECG, HRV, and T-wave amplitude per script were derived off-line. Respiration rate was not taken into account in the present study.
1.2.3.4. Blood pressure. The blood pressure was recorded continuously with the vascular unloading method by using a fin-a-press tonometer (TNO Biomedical Instruments). This device derives the systolic and diastolic blood pressure noninvasively from a pulse wave on a beat-by-beat basis by placing a cuff around the first finger (pointing finger) of the non-dominant hand. Arterial volume is measured using a servo-controlled photoplethysmograph. Prior to the start of the experiment, the fin-a-press tonometer was calibrated for each participant. To prevent confounding effects of skin temperature and movement, participants were asked to place the hand with the fin-a-press cuff on a towel and were instructed not to move their arm during the imagery.

1.2.3.5. Skin conductance level (SCL). The skin conductance level was recorded using a Schwarzer EDA48 Amplifier using the method of constant voltage (.5 volts). Two $.70 \mathrm{~cm} \mathrm{Ag} / \mathrm{AgCl}$ surface electrodes were filled with isotonic paste and attached to the palmar side of the middle phalanges of the second and third fingers of the nondominant hand.

The EMG and ECG signals were fed through a Picker/Schwarzer Coupler (ED14/ 12) 12 channel EEG measurement amplifier to a PXI data-acquisition system (PXI 4472; National Instruments) using a low pass filter with a time constant of .3 s. A $1000-\mathrm{Hz}$ sample frequency was used. Further, possible $50 \mathrm{~Hz}$ interference was eliminated using a notch filter. Additionally, a high pass filter of $1.60 \mathrm{~Hz}$ and a low pass filter of $300 \mathrm{~Hz}$ were used. Skin conductance and blood pressure were fed through a $500-\mathrm{Hz}$ anti-aliasing filter directly to the PXI data acquisition system. All data were recorded and stored using the lab server for further off-line processing.

\subsubsection{Imagination scripts}

Participants were asked to imagine as vividly as possible the following scripts: neutral, core disgust, and A-R disgust (see Appendix A for a full description of all scripts). A prerecording was made for all scripts while being read by an experimenter. They were stored as audio files (16 bit wav-files) on the lab computer (Dell GX270, Pentium 4A, 3 GHz, Windows 2000 Service Pack 4) which the experimenter could control to enable a synchronized presentation and data acquisition. The scripts were presented via speakers. In earlier research in our lab, these scripts successfully induced disgust (e.g., de Jong et al., 2002).

\subsubsection{Visual analog scale (VAS)}

Five VAS's were administered. Participants rated on a $100-\mathrm{mm}$ line their ability to imagine the scripts, whether they had experienced fear, disgust, dizziness, and a tendency to vomit during the scripts.

\subsection{Procedure}

The experiment was conducted at the Department of Clinical Psychological Science in a 'soundproof' room, separated from the data-recording lab by means of a 'one-way' screen. To avoid confounding effects by caffeine or other food substances on blood pressure, participants were instructed not to eat or drink anything in the $2 \mathrm{~h}$ prior to the experiment. On arrival at the lab, participants had to provide informed consent following a brief introduction and completed a package of questionnaires, containing the MBPI, MFS (full version), BIQ DS, DQ and the DPSSR. After this, the participant was hooked up to all physiological instruments. Given the potential risk of vasovagal fainting to occur during the experiment (in particular in the high fearful group during A-R imagery), the experimenter was not blind to group membership of the participants. To minimize the influence of eye-blink responses on the EMG signals and to make sure that the participants fully concentrated on the content of the scripts presented, the participants were instructed to close their eyes during the imagination procedure. Before presenting the scripts, participants received a 5-min resting period in order to habituate to the laboratory setting. After dimming the lights, the scripts were presented. Each script lasted about $5 \mathrm{~min}$. Before and after each script, participants completed the VASs and were asked to rinse their mouth with a sip of water. To minimize the influence of undesirable carry over effects we presented the scripts as follows: neutral script, core disgust script or A-R script (the order in which these two disgust scripts were presented was counterbalanced). After this, all electrodes and cuffs were removed and the participant received a small financial incentive $(10 €)$ for participating.

\subsection{Data reduction}

First, physiological data for EMG signals were digitally rectified, and integrated with a time constant of $.3 \mathrm{~s}$ using specifically designed software programs. Mean levator labii and corrugator activity during each of the scripts was calculated. Similarly, for systolic and diastolic blood pressure and skin conductance level, mean levels during each script were determined. If values were outside the normal range $(\geq 3$ S.D.s) for systolic blood pressure, diastolic blood pressure, and skin conductance, signals were visually inspected and possibly rejected as artefacts. Next, in line with recommendations by Shapiro et al. (1996), mean arterial pressure (MAP) was calculated using the following formula: DBP + 1/3 (SBP - DBP).

The ECG signal was analysed off-line with specifically designed software to detect the R-waves and the various components comprising the T-wave amplitude 
(P-, Q- and R-waves). The T-wave amplitude was computed by the difference in $\mu \mathrm{V}$ between the maximum value included in a $100-300 \mathrm{~ms}$ window after the R-wave and the mean value of the 40-ms isoelectric line between P-wave and Q-wave (Rau, 1991). If the software could not identify a P-, Q-, or R-wave, the signal was rejected as an artefact. Next, the mean amplitude during the scripts was calculated. The Twave amplitude indicates a withdrawal of sympathetic activity (Kline et al., 1998).

Heart rate variability was defined as the variability of the intervals between successive heart beats (R-tops of the ECG). Usually, three components are distinguished: low frequency, middle frequency and high frequency. The high frequency component is under the influence of the nervus vagus, and therefore is the most likely index for parasympathetic activity (Task Force of the European Society of Cardiology and the North American Society of Pacing Electrophysiology, 1996). Therefore, only the power in this high frequency band (HF: .15-.40 Hz) was studied in this experiment. The CARSPAN software package (version 2.11; IEC ProGamma, Groningen, the Netherlands) was used to correct the inter-beatintervals (IBI) and calculate the power in the HF band by means of spectral analysis on the IBIs according to a discrete Fourier transform algorithm. CARSPAN was also used to correct possible artifacts in the ECG signals by replacing artefactual data by estimating an interpolation from both preceding and succeeding intervals. All data were visually inspected to ensure adequate corrections. After obtaining the HF band of heart rate variability, in accordance with recommendations by the Task Force of the European Society of Cardiology and the North American Society of Pacing Electrophysiology (1996), normalized units were calculated for the power in the HF-band by means of this formula: HF power/(total power - VLF) $\times 100$. This was done for each script.

Due to technical difficulties, blood pressure was not measured in three persons in the non-blood-fearful group, and for one non-blood-fearful individual all physiological data were lost. Further, for one person in the blood-fearful group, data for corrugator and levator was only partially recorded whereas for two others in that group, data for heart rate variability were not available. For one of these, all cardiac data were unavailable.

\subsection{Statistical analyses}

Missing values were observed only on the MFS and DQ $(<1 \%)$ and were extrapolated using SPSS' missing value analysis. This technique imputes missing data via regression. Next, a test on the means of both the high and low blood fear group was conducted to establish whether the two groups indeed differed with respect to blood fearfulness and on disgust propensity and sensitivity.

To determine whether the two disgust scripts elicited a distinct subjective and physiological response pattern, a series of repeated measurement ANOVAs was performed. Two a priori contrasts were specified. In order to determine whether guided imagery of the two disgust types elicited subjective (emotions, symptoms) and physiological responses, the first contrast compared both disgust scripts with the neutral script. To examine whether the different disgust types displayed a distinct reaction pattern, the second contrast compared the subjective and physiological responses during the core disgust script versus the reaction during the A-R disgust script. Further, the group variable was included in all analyses to determine whether high and low blood-fearful individuals reacted differently to both disgust types, or to A-R disgust specifically ${ }^{1}$.

The analyses were conducted in this order: self-report indices, general physiological arousal and disgust indices (facial EMG of corrugator and disgustspecific levator labii, skin conductance level), core disgust parameter (saliva production), A-R disgust parameters (power in HF band of heart rate variability, Twave amplitude, and mean arterial pressure).

\section{Results}

\subsection{Descriptives}

As expected, the high blood-fearful group scored significantly higher than the low blood fear group on fear of blood (BIQ MFS, MBPI), disgust propensity (DS, DQ, DPSS-RP) and disgust sensitivity (DPSS-RS). Table 1 presents a summary of these findings. Next, a 2 (scale: DS-core disgust, DS-AR disgust) $\times 2$ (group: high, low blood fearful) ANOVA was performed to determine whether high blood-fearful individuals displayed elevated disgust propensity specifically for A-R stimuli. Most importantly for the present context, the interaction term scale $\times$ group $(F(1,58)=5.48, p=.02$, $\left.\eta_{p}^{2}=.09\right)$ and a series of post hoc paired sample $t$-tests showed

\footnotetext{
${ }^{1}$ First, a one-way ANOVA compared the mean physiological activity on all parameters between the high and low blood-fearful participants during the neutral script. Only corrugator activity and saliva production were significantly higher in the high blood-fearful group.
}

Table 1

Mean scores on all questionnaires (MBPI, MFS, BIQ, DS, DQ, and DPSS-R) for the high and low blood-fearful groups

\begin{tabular}{lcccrc}
\hline Indices & HBF $(n=30)$ & LBF $(n=30)$ & Possible range & $t(58)$ & $p$ \\
\hline MBPI total & $63.50(23.11)$ & $8.30(8.67)$ & $0-160$ & -12.25 & $<.01$ \\
MFS total & $74.23(30.30)$ & $21.37(12.14)$ & $0-200$ & -8.87 & $<.01$ \\
BIQ-Fear & $27.83(6.53)$ & $14.70(3.20)$ & $10-50$ & -9.89 & $<.01$ \\
BIQ-Faint & $11.37(2.17)$ & $10.10(.40)$ & $10-30$ & -3.14 & $<.01$ \\
DS total & $19.55(3.97)$ & $14.02(3.87)$ & $0-32$ & -5.46 & $<.01$ \\
Core & $11.73(2.92)$ & $9.23(2.86)$ & $0-18$ & -3.35 & $<.01$ \\
A-R & $12.97(2.31)$ & $8.80(2.92)$ & $0-18$ & -6.13 & $<.01$ \\
DQ total & $114.30(36.78)$ & $142.77(36.54)$ & $24-216$ & 3.01 & $<.01$ \\
DPSS-RP & $23.70(4.40)$ & $17.90(3.14)$ & $16-80$ & -5.87 & $<.01$ \\
DPSS-RS & $19.63(4.94)$ & $13.80(3.21)$ & $16-80$ & -5.43 & $<.01$ \\
& & & & & 60 \\
Valid N & & & & & \\
\hline
\end{tabular}

Abbreviations: $\mathrm{HBF}=$ high blood fearful, $\mathrm{LBF}=$ low blood fearful, $\mathrm{MBPI}=$ multidimensional blood/injury phobia inventory, MFS = medical fear survey, BIQ = blood-injury phobia questionnaire, DS = disgust scale, $A-R=$ animal-reminder subscale, DQ = disgust and contamination sensitivity questionnaire, DPSS-RP = disgust propensity and sensitivity scale-revised propensity, DPSS-RS= disgust propensity and sensitivity scale-revised sensitivity. Note: standard deviations are described in parentheses.

that the high blood-fearful group scored significantly higher on DSAR than on DS-core $(t(29)=-2.48 ; p=.02)$, whereas the low bloodfearful group displayed no differences between the DS-subscales $(t(29)=.85 ; p=.40)$. So, although the high blood-fearful participants scored higher on both core and A-R disgust propensity, elevated disgust propensity in this group was most pronounced for A-R disgust.

\subsection{Differential reactivity to the disgust scripts}

All means and standard deviations of the subjective and physiological parameters can be found in Table 2 .

\subsubsection{Self-report}

2.2.1.1. Imaginary ability. A 3 (script: neutral, A-R disgust, core disgust) $\times 2$ (group: high, low blood fearful) ANOVA was performed for the ability to imagine the scripts. The interaction term script $\times$ group was not significant $(F(2,57)=.41, p=.66$, $\left.\eta_{p}^{2}=.01\right)$. The script effect was significant, indicating that some scripts could be better imagined than others $(F(2,57)=3.76$, $\left.p=.03, \eta_{p}^{2}=.12\right)$. Post hoc contrasts revealed that overall, participants could imagine the A-R script less well than the neutral script $\left(F(1,58)=7.65, p<.01, \eta_{p}^{2}=.12\right)$. Yet, although the core script was imagined equally well to the neutral script $(F(1$, $\left.58)=1.37, p=.25, \eta_{p}^{2}=.03\right)$, no differences were observed between the imaginability of the core and A-R script $(F(1$, $\left.58)=2.04, p=.16, \eta_{p}^{2}=.03\right)$. Further, high and low fearful participants did not differ in their ability to imagine either script $\left(F(1,58)=.21, p=.65, \eta_{p}^{2}=.01\right)$.

2.2.1.2. Differential emotional reactivity. A 2 (emotion: disgust, fear) $\times 3$ (script: neutral, A-R disgust, core disgust) $\times 2$ (group: high, low blood fearful) ANOVA revealed significant script $(F(2$, $\left.57)=99.70, p<.01, \eta_{p}^{2}=.78\right)$, script $\times$ emotion $(F(2,57)=70.81$, $\left.p<.01, \eta_{p}^{2}=.71\right)$ and script $\times$ group $(F(2,57)=5.39, p=.01$, $\left.\eta_{p}^{2}=.16\right)$ effects. The third order interaction script $\times$ emotion $\times$ group was not significant $(F(2,57)=1.54, p=.22$, $\left.\eta_{p}^{2}=.05\right)$. Planned contrasts for the script effect showed that both disgust scripts evoked stronger emotions than the neutral script $\left(F(1,58)=192.70, p<.01, \eta_{p}^{2}=.77\right)$, but that there was no difference between the core and A-R disgust scripts $(F(1,58)=1.98$, $\left.p=.17, \eta_{p}^{2}=.03\right)$. Furthermore, the significant contrast "disgust 
Table 2

Means (standard deviations) of the self-report and physiological parameters for all scripts as a function of blood fear

\begin{tabular}{|c|c|c|c|c|c|c|}
\hline & \multicolumn{2}{|l|}{ Neutral } & \multicolumn{2}{|l|}{ Core disgust } & \multicolumn{2}{|l|}{ A-R disgust } \\
\hline & LBF & $\mathrm{HBF}$ & LBF & $\mathrm{HBF}$ & LBF & $\mathrm{HBF}$ \\
\hline \multicolumn{7}{|l|}{ Self-report } \\
\hline Imagine & $74.10(20.06)$ & $78.30(16.64)$ & $71.43(24.07)$ & $73.77(16.74)$ & $68.57(21.81)$ & $67.33(21.41)$ \\
\hline Disgust & $1.43(2.99)$ & $6.93(14.02)$ & $42.20(26.88)$ & $63.63(22.71)$ & $31.93(29.42)$ & $57.47(20.71)$ \\
\hline Fear & $2.10(4.20)$ & $10.97(12.33)$ & $8.00(12.44)$ & $23.53(19.45)$ & $9.13(12.00)$ & $27.50(18.50)$ \\
\hline Vomit & $.97(1.87)$ & $5.50(14.16)$ & $8.53(16.17)$ & $40.13(29.45)$ & $2.67(7.07)$ & $24.90(28.01)$ \\
\hline Dizzy & $1.67(2.94)$ & $2.77(5.48)$ & $2.97(7.32)$ & $9.40(11.50)$ & $1.77(3.43)$ & $7.97(12.01)$ \\
\hline \multicolumn{7}{|c|}{ General parameters } \\
\hline Lev $(\mu \mathrm{V})$ & $9.26(3.40)$ & $10.73(4.83)$ & $10.83(6.62)$ & $1342(4.98)$ & $10.92(5.90)$ & $14.33(6.38)$ \\
\hline $\operatorname{Corr}(\mu V)$ & $9.11(3.91)$ & $13.39(9.89)$ & $9.28(4.05)$ & $15.73(9.04)$ & $9.20(3.01)$ & $15.53(9.04)$ \\
\hline $\mathrm{SCL}(\mu \mathrm{S})$ & $1.65(.92)$ & $1.45(.94)$ & $1.65(.85)$ & $1.57(1.06)$ & $1.71(.83)$ & $1.61(1.10)$ \\
\hline \multicolumn{7}{|c|}{ Digestive component } \\
\hline Saliva (g) & $1.71(1.20)$ & $2.67(1.84)$ & $1.69(1.22)$ & $3.02(2.11)$ & $1.73(1.15)$ & $3.23(2.41)$ \\
\hline \multicolumn{7}{|c|}{ Cardiac components } \\
\hline $\mathrm{HRV}(\mathrm{nu})$ & 71.03 (31.60) & $64.55(29.62)$ & $65.89(30.63)$ & $52.00(20.02)$ & $50.71(114.61)$ & $62.52(42.17)$ \\
\hline T-wave $(\mu \mathrm{V})$ & $333.32(130.09)$ & $316.00(129.06)$ & $345.73(136.70)$ & $324.70(130.85)$ & $343.60(137.71)$ & $324.89(130.84)$ \\
\hline MAP (mmHg) & $92.39(11.20)$ & $92.51(12.46)$ & $91.86(10.73)$ & $94.45(12.45)$ & $92.82(9.34)$ & $93.75(12.58)$ \\
\hline Valid $N$ & & & & & & 60 \\
\hline
\end{tabular}

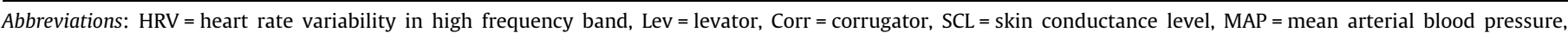
$\mathrm{LBF}=$ low blood-fearful group, $\mathrm{HBF}=$ high blood-fearful group; $\mathrm{g}=$ grams; nu = normalized units. Standard deviations are presented in parentheses

scripts versus the neutral script" for the script $\times$ emotion effect $\left(F(1,58)=139.16, p<.01, \eta_{p}^{2}=.71\right)$ revealed that specifically for the disgust scripts, the experience of disgust is stronger than that of fear. The contrast "A-R versus core disgust" was significant $\left(F(1,58)=14.26, p<.01, \eta_{p}^{2}=.20\right)$, showing that the core disgust script evoked stronger disgust than the A-R script. Finally, the contrasts for the script $\times$ group interaction indicated that high blood fearfuls experienced higher levels of fear and disgust than low blood fearfuls during both disgust scripts compared to the neutral script $\left(F(1,58)=10.77, p<.01, \eta_{p}^{2}=.16\right)$. This effect was similar for both types of disgust scripts $(F(1,58)=.74, p=.39$, $\left.\eta_{p}^{2}=.01\right)$.

2.2.1.3. Vasovagal versus digestive symptoms. A 2 (response: dizziness, tendency to vomit) $\times 3$ (script: neutral, A-R disgust, core disgust) $\times 2$ (group: high, low blood fearful) ANOVA revealed significant script $\left(F(2, \quad 57)=21.77, \quad p<.01, \quad \eta_{p}^{2}=.43\right)$, script $\times$ response $\left(F(2, \quad 57)=18.23, \quad p<.01, \quad \eta_{p}^{2}=.39\right) \quad$ and script $\times$ group $\left(F(2,57)=11.08, p<.01, \eta_{p}^{2}=.32\right)$ effects. The third order interaction script $\times$ response $\times$ group was also significant $\left(F(2,57)=7.48, p<.01, \eta_{p}^{2}=.21\right)$. Planned contrasts for the script effect showed that both disgust scripts evoked stronger symptoms than the neutral script $(F(1,58)=43.01, p<.01$, $\left.\eta_{p}^{2}=.42\right)$ and the core disgust script evoked stronger symptoms than the A-R disgust script $\left(F(1,58)=12.91, p<.01, \eta_{p}^{2}=.18\right)$. Both planned contrasts for the script $\times$ response effect were significant, demonstrating that the tendency to vomit was stronger than the experience of dizziness during the disgust scripts $(F(1$, $58)=28.49, p<.01, \eta_{p}^{2}=.33$ ) and that this difference was more prominent during the core disgust script than the A-R disgust script $\left(F(1,58)=11.85, p<.01, \eta_{p}^{2}=.17\right.$; see Table 2$)$. The first planned contrast (disgust vs. neutral) for the script $\times$ group interaction and the script $\times$ response $\times$ group interaction indicated that high blood fearfuls generally experienced symptoms more strongly than low blood fearfuls during the disgust scripts $\left(F(1,58)=22.37, p<.01, \eta_{p}^{2}=.28\right)$, yet this was most apparent for the tendency to vomit during the disgust scripts $(F(2,57)=13.39$, $p<.01, \eta_{p}^{2}=.19$ ). The second planned contrast (core disgust vs. A-R disgust) did not reach significance for the script $\times$ group interaction $\left(F(1,58)=2.11, p=.15, \eta_{p}^{2}=.04\right)$ nor the script $\times$ response $\times$ group interaction $\left(F(2,57)=2.90, p=.09, \eta_{p}^{2}=.05\right)$. Thus, high blood fearfuls experienced more dizziness and especially a stronger tendency to vomit than low blood fearfuls independent of the type of disgust elicitor.

\subsubsection{General disgust and arousal parameters}

2.2.2.1. Levator labii. A 3 (script: neutral, A-R disgust, core disgust) $\times 2$ (group: high, low blood fearful) ANOVA was performed for the disgust-specific $m$. levator. The interaction term script $\times$ group did not reach significance $(F(1,55)=.61$, $\left.p=.55, \eta_{p}^{2}=.02\right)$. Yet, the main effect script was significant $(F(2$, $55)=4.87, p=.01, \eta_{p}^{2}=.15$ ). The first contrast for script indicated that levator activity increased during the two disgust scripts compared to the neutral script $\left(F(1,56)=9.80, p<.01, \eta_{p}^{2}=.15\right)$. The second planned contrast showed that levator activity did not differ between the A-R and core disgust script $(F(1,56)=.73$, $\left.p=.40, \eta_{p}^{2}=.01\right)$.

2.2.2.2. Corrugator. A 3 (script: neutral, A-R disgust, core disgust) $\times 2$ (group: high or low blood fearful) ANOVA was performed for the $\mathrm{m}$. corrugator. The interaction term script $\times$ group was not significant $\left(F(2,55)=1.96, p=.15, \eta_{p}^{2}=.07\right)$ and neither was the main effect script $\left(F(2,55)=2.40, p=.10, \eta_{p}^{2}=.08\right)$, so the two disgust scripts did not evoke increases in corrugator activity compared to the neutral script.

2.2.2.3. Skin conductance level. A 3 (script: neutral, A-R disgust, core disgust) $\times 2$ (group: high or low blood fearful) ANOVA was performed for skin conductance level. The interaction term script $\times$ group was not significant $(F(2,56)=1.25, \quad p=.29$, $\left.\eta_{p}^{2}=.04\right)$, so both high and low blood-fearful individuals displayed similar patterns of skin conductance during the various scripts. The main effect script was significant $\left(F(1,58)=3.91, p=.03, \eta_{p}^{2}=.12\right)$. Planned contrasts showed that compared to the neutral script, the two disgust scripts induced increases in skin conductance level $\left(F(1,57)=5.56, p=.02, \eta_{p}^{2}=.09\right)$. The second contrast revealed that skin conductance level generally did not differ between the A$\mathrm{R}$ disgust script and the core disgust script $(F(1,57)=2.67, p=.11$, $\left.\eta_{p}^{2}=.05\right)$. 


\subsubsection{Core disgust parameter}

2.2.3.1. Salivary excretion. A 3 (script: neutral, A-R disgust, core disgust) $\times 2$ (blood fear: high or low) ANOVA was performed on salivary excretion in grams. Both the interaction term script $\times$ group $\left(F(2,57)=2.47, p=.09, \eta_{p}^{2}=.08\right)$ and the main effect script $\left(F(2,57)=2.54, p=.09, \eta_{p}^{2}=.08\right)$ approached significance. Contrasts for main effect script showed that overall, participants produced significantly more saliva during the two disgust scripts compared to the neutral script $(F(1,58)=4.91$, $\left.p=.03, \eta_{p}^{2}=.08\right)$. Yet, the salivary excretion did not differ significantly between A-R script and the core disgust script ( $F(1$, $58)=1.41, p=.24, \eta_{p}^{2}=.02$ ). For script $\times$ group, the salivary excretion was greater in the high blood-fearful group compared to the low fearful group during the two disgust scripts versus the neutral script $\left(F(2,57)=5.02, p=.03, \eta_{p}^{2}=.08\right)$. The second contrast showed that the difference in saliva production during A-R disgust versus the core disgust script did not differ between the two groups $\left(F(1,58)=.59, p=.45, \eta_{p}^{2}=.01\right)$.

\subsubsection{A-R parameters}

2.2.4.1. Heart rate variability. A 3 (scripts: neutral, A-R disgust, core disgust) $\times 2$ (group: high or low blood fearful) ANOVA was performed for power in normalized units in the high frequency band. The interaction term script $\times$ group was not significant $(F(2$, $54)=1.86, p=.17, \eta_{p}^{2}=.06$ ) while main effect script did approach significance $\left(F(2,54)=2.51, p=.09, \eta_{p}^{2}=.09\right)$. Contrasts for the main effect script demonstrated that heart rate variability did not differ during the two disgust scripts compared to the neutral script $\left(F(1,55)=1.46, p=.23, \eta_{p}^{2}=.06\right)$ nor between the A-R script and the core disgust script $\left(F(1,55)=.04, p=.83, \eta_{p}^{2}=.01\right)$.

2.2.4.2. T-wave amplitude. For the T-wave amplitude, a 3 (script: neutral, A-R disgust, core disgust) $\times 2$ (group: high or low blood fearful) ANOVA was performed. The interaction term script $\times$ group was not significant $\left(F(1,55)=.26, p=.78, \eta_{p}^{2}=.01\right)$. The main effect script was significant $\left(F(1,55)=9.10, p<.01, \eta_{p}^{2}=.25\right)$. Next, planned contrasts for the main effect script showed that generally, participants responded to the two disgust scripts with an increase in T-wave amplitude compared to the neutral script $(F(1,56)=18.47$, $p<.01, \eta_{p}^{2}=.25$ ) but no significant differences were observed in Twave amplitude during the A-R script versus the core disgust script $\left(F(1,56)=.18, p=.68, \eta_{p}^{2}=.01\right)$.

2.2.4.3. Mean arterial pressure. A 3 (script: neutral, A-R disgust, core disgust) $\times 2$ (group: high or low blood fearful) ANOVA was performed for the mean arterial pressure. The interaction term script $\times$ group was significant $\left(F(2,53)=3.31, p=.04, \eta_{p}^{2}=.11\right)$. The main effect script $\left(F(2,53)=1.29, p=.28, \eta_{p}^{2}=.05\right)$ was not significant. For the interaction term script $\times$ group, planned contrasts revealed that a border-significant increase was observed in mean arterial pressure during the two disgust scripts, but only in the high blood-fearful participants $(F(1,54)=2.93, p=.09$, $\left.\eta_{p}^{2}=.05\right)$. Further, the second contrast revealed a bordersignificant effect $\left(F(1,54)=3.19, p=.08, \eta_{p}^{2}=.06\right)$. Thus, mean arterial pressure tended to be lower during the core disgust script compared to the A-R disgust script in low blood-fearful participants, while the reverse appeared true for the high blood-fearful group.

\section{Discussion}

The present study represents the first attempt to test the idea of differential responsivity of cardiovascular and digestive compo- nents of the ANS during core and A-R disgust. The main findings were: (a) guided imagery of disgust elicited a physiological response pattern characterized by an increase in saliva production, T-wave amplitude and EMG activity of the m. levator labii, (b) A-R and core disgust did not evoke a distinct physiological response pattern in this respect, yet (c) overall, the core disgust script did evoke stronger subjective experiences than the A-R script (i.e., stronger disgust, fear, dizziness and tendency to vomit), and finally (d) disgust-induced subjective responsivity was most pronounced in high blood-fearful individuals, although this was not mimicked by stronger physiological reactivity.

In line with earlier research (e.g., Vrana, 1993, de Jong et al., 2002), guided imagery successfully elicited self-reported feelings of disgust and induced disgust-specific activity in facial EMG (i.e., increased activity of the $\mathrm{m}$. levator labii). Most relevant for the present context, the elicited feelings and expressions of disgust during the core and A-R disgust scripts were accompanied by changes in activity in the digestive as well as the cardiac components of the ANS. For the digestive component, increases were observed in saliva production, which most likely indicates an increase in parasympathetic activity (Proctor and Carpenter, 2007). For the cardiac components, increases were observed in T-wave amplitude which generally can be taken to indicate sympathetic withdrawal (Kline et al., 1998). There was no evidence for increased parasympathetic activity of the cardiac component of the ANS; participants' heart rate variability (represented by power in the HF band) remained unaffected by the disgust induction.

The disgust-induced physiological changes were paralleled by a rise in subjective indicators of digestive and cardiac reactivity (i.e., vomit tendencies and feelings of dizziness, respectively). These subjective symptoms were significantly stronger during the core disgust than during the A-R disgust script. This was not the case for the physiological indices. By and large, the physiological response pattern was very similar for core and A-R disgust. Previous research indicated that core and A-R disgust can be reliably distinguished from each other on a subjective level (Olatunji et al., 2007). So it appears that although the content of elicitors in A-R disgust may have gradually evolved away from core disgust elicitors (Rozin and Fallon, 1987; Rozin et al., 1999a,b), the autonomic response program for both disgust types remained the same: a defensive response program shielding the organism from contamination by pathogens. This may also explain why mainly the digestive component of the PNS became activated in the present disgust imagery procedures, as vomiting is responsible for the expulsion of potentially hazardous pathogens from the body (e.g., by vomiting) (Guyton and Hall, 2006).

For both types of disgust-imagery, the pattern of disgustinduced ANS reactivity was largely similar for high and low bloodfearful individuals, and no evidence emerged to indicate that high blood-fearful individuals showed an increase in parasympathetic cardiac activity during (A-R) disgust and/or decrease in mean arterial pressure. This contradicts the idea that specifically people who respond with a greater parasympathetic activity (and subsequent drop in blood pressure) during confrontation with (A-R) disgust stimuli are at risk for developing blood phobia (e.g., as these people may be more prone to emotional fainting; de Jong and Merckelbach, 1998). In addition, these results are in apparent contrast with the earlier findings that blood-fearful individuals did demonstrate parasympathetic reactivity in cardiac measures during exposure to blood-related stimuli (e.g., surgery films), such as a decrease in blood pressure (Öst et al., 1984; Rohrmann and Hopp, 2008; Vögele et al., 2003) or an increase in heart rate followed by an abrupt drop (Palomba et al., 2000; Sarlo et al., 2002). However, because all of these earlier studies used bloodrelated material, it may well be that a diphasic response in cardiac 
components may be specific to blood rather than for (A-R) disgust stimuli in general.

Although high and low blood-fearful participants showed a very similar physiological response pattern, marked differences were evident at the subjective level. Irrespective of the type of disgust imagery, high blood-fearful participants generally experienced stronger increases in subjective emotional reactivity (both disgust and fear), and a relatively strong experienced tendency to vomit and feelings of dizziness in response to the disgust scripts. The differences in subjective symptoms (dizziness and vomit tendencies) between the high and low blood-fearful participants were most pronounced for the core rather than the A-R script. This is particularly noteworthy since this contradicts earlier postulations that a propensity for A-R stimuli may be associated with specific symptomatology in blood phobia (i.e., fainting; de Jong and Merckelbach, 1998).

Sustaining the alleged role of (subjective) disgust in blood phobia and consistent with the present finding that high bloodfearful individuals experienced relatively strong disgust during disgust imagery, they also reported a stronger habitual tendency to respond with disgust in response to a variety of potential disgust elicitors than low fearful individuals. In line with earlier research (de Jong and Merckelbach, 1998), elevated disgust propensity was most pronounced for A-R disgust. In apparent contrast with this, the enhanced experience of disgust in high blood-fearful individuals during the present imagery procedure was similar for A-R and core disgust imagery. Interestingly, blood-fearful participants not only displayed elevated levels of disgust propensity but also heightened disgust sensitivity (the tendency to evaluate the experience of disgust more negatively). These findings are in line with recent indications that disgust sensitivity could play a pivotal role in the etiology of blood fear (e.g., van Overveld et al., 2006). As high blood-fearful individuals generally experience disgust in response to blood (Tolin et al., 1997), it may well be that an extreme sensitivity for experiencing disgust induces an avoidance pattern for the physical correlates of disgust, rather than the confrontation with blood stimuli per se.

Some comments are in order regarding the methodological aspects of the current experiment. First, it could be that the imagination procedure itself influenced the results of the response patterns. For example, the use of imagination procedures renders it difficult to establish whether participants intentionally decide to imagine certain scripts less vividly to avoid possible aversive consequences (i.e., fainting). From that perspective, it would be interesting to compare imagery with other types of elicitors (e.g., using film clips or behavioral approach experiments) to examine if these would yield different results. In one of the few studies comparing guided imagery of disgust with an intense (core) disgust film, both methods successfully induced disgust as reflected by self-report and facial EMG, yet, only the pattern following the film clip differentiated between high and low (spider) fearful groups (de Jong et al., 2002).

Second, the present design only included neutral and disgusting materials. Therefore, it remains to be established whether the physiological reactivity in response to the disgust scripts are specific to disgust or could be associated with other emotions as well. Thus, future research may consider including scripts on both negative (i.e., fear) and positive emotions (i.e., happiness) to determine the specificity of the various parameters to disgust. Additionally, although the A-R script did evoke disgust and did not differ in imaginability compared to the other scripts, it may be argued that the A-R script was relatively bizarre. Consequently, the A-R disgust script may not have been as effective as the other script types in inducing its alleged concomitant physiological response pattern.
Third, the order of presentation of the scripts was relatively fixed in the sense that the neutral script was always presented prior to the disgust scripts in an attempt to prevent undesirable carry-over effects from the disgust script on the neutral condition. Thus, any differences between the neutral and the two disgust scripts may be explained in terms of habituation or cross-over effects. At least some of the present parameters are known for their short-lived and event-related reactivity (i.e., levator labii) so these may be less sensitive to cross-over and habituation effects. It might have been more problematic for other measures (i.e., SCL and power in the HF band). Yet, no changes were noted in HRV during the disgust scripts compared to the neutral script, whereas SCL increased rather than decreased during the disgust scripts. This is in apparent contrast with a habituation explanation, and in line with recent work that found similar elevations in SCL during disgusting film clips (Rohrmann and Hopp, 2008). Thus, it appeared that habituation and/or the order of presentation of the scripts did not play a major role in the present pattern of findings.

In conclusion, the present findings indicated that inducing disgust coincided with an increase in parasympathetic activity (i.e., saliva production), a reduction in sympathetic activity (i.e., increases in T-wave amplitude) and increases in facial EMG of the $\mathrm{m}$. levator. In conflict with the proposed role of disgust-induced autonomic activity in blood phobia (Page, 1994), the disgustinduced physiological reactivity was not particularly pronounced in high blood-fearful participants. Germane to this, physiological activation was shown to be relatively independent of the type of disgust elicitor (core versus A-R). We therefore propose that the physiological reaction pattern of core disgust functions as a hardwired defensive mechanism to protect the individual against contamination with possible pathogens, and provides a basis for all disgust reactions.

\section{Acknowledgements}

The present authors wish to express their gratitude to Franca Leeuwis for her efforts in the process of data acquisition.

\section{Appendix A. Neutral}

You are about to look up a friend who has moved to another city. You are standing at the platform of the station, waiting for the right train. Concentrate on what you see on the station. Pay attention to all the sounds which you hear. A man comes by with strong aftershave. Concentrate yourself on the fragrance. Gradually it becomes more busy at the platform. Concentrate yourself on what you observe when the train approaches the platform. You are standing at the door with two other people. You get in the train. You are searching for a seat. Pay attention to what you see. You have found a seat. You lay down your stuff and will sit down. Concentrate yourself on your surroundings. Look around the carriage to see what kind of people sit there. How do they look? What are they doing? Concentrate on what you hear. You look outside. What do you see if you look outside? The conductor comes in and asks for the tickets. What does he look like? What happens when he enters the carriage? You look in your pockets to grab your ticket. You show your ticket to the conductor. On your watch you notice that in some minutes, you will arrive at the station of your destination. The train decreases in speed. Concentrate yourself on what you feel in your body when the train slows down. You have arrived at your end destination. Consider what it looks like when the train drives in the station. Concentrate on what you hear. Concentrate yourself on what happens in the carriage. You take your case and get up. You are walking through the station in search 
of the exit. What does the station look like? Concentrate yourself on what you hear. You follow the stream of people towards the exit. Concentrate yourself on how you feel. From your friend you obtained a route description. Following the route description, you walk through the streets of the city. What do you see around you? Which people are walking there? Concentrate on the sounds of the city. You reach the street where you must be. Halfway the street you discover the house number where you must be. You ring and your friend opens the door.

\section{Appendix B. Oral disgust}

You work as an assistant in home care. You open the door at an old man. You hear from the sounds coming from the chamber that something is wrong. Concentrate yourself on what you hear. You open the door. The man appears sick and has vomited. Apparently he was not able to reach the bathroom in time. Concentrate yourself on what you smell. Which fragrances can you distinguish? Concentrate yourself on what you see. What does the man look like? How does he sit? You walk up to the man. Concentrate yourself on the fragrance. Pay attention to the details which you see now. What does his shirt look like? See how fresh vomit mixes with the dried-up remains of vomit from an hour ago. Concentrate on the face of the man, what does this look like? Observe the lumps of vomit that drip down along his chin. The man vomits again. Concentrate yourself on his body. What do you see happening? Concentrate yourself on his face. Concentrate on the sounds of vomiting. Take in the sourish fragrance. What does the goo look like that the man spits out? You are gagging. Concentrate yourself on what you feel happing in your stomach, throat and mouth. Incorporate the sourish taste in your mouth. Some splashes of vomit spatter on your hands and your face. How do you feel? While you help the man out of his clothing, you notice that he is defecating himself. Concentrate yourself on what you see, what you smell and what you hear. You are helping the man. Concentrate on your physical feelings. You are washing the man. What does this look like? Which operations do you have to perform? What does this do to you?

\section{Appendix C. Animal-reminder disgust}

You are sitting at a square. Directly across you sits a somewhat dirty looking man. Look closely at the man. Pay attention to what you see. You look at to the face of the man and you see that his right eye is not real. Concentrate yourself on what you feel. You look more closely and notice that his right eye is made of glass. What does it look like? Concentrate on what you see and how you feel. You look at the man. You look at his face with his glass eye. Pay attention to what you see. Then, the man brings a spoon to his glass eye. He puts the spoon behind his eye and hops the eye from its socket. Concentrate yourself on what you see and what you hear. Concentrate on your feelings. Pay attention to your pulse and your breathing. You look at the empty cavity where the glass eye used to be. Concentrate yourself on the empty eye socket. Pay attention to what the empty cavity looks like. Concentrate yourself on what you see and how you feel. You look at to the spoon bearing the glass eye. Concentrate yourself on the spoon with the glass eye. You look at the man and you see that he is now taking out a cow's eye. Concentrate on how the cow's eye looks like. Pay attention to what you feel. You see the cow's eye lying on the hand of the man. The man studies the eye from all sides. Pay attention to what you see. Concentrate on what you feel. After the man has inspected the cow's eye thoroughly, you see how he brings the eye to his face. Concentrate yourself on what you see and how you feel. The man takes the cow's eye in the direction of the empty eye socket.
Then, he puts the cow's eye in his own empty eye socket. What does this do to you? Pay attention to what you see. Concentrate on what you feel. Pay attention to your pulse and your breathing. You look closely at the man again and look at the cow's eye that is now in the face of the man. Concentrate yourself on the cow's eye in the face of the man. Pay attention to what you see. At that moment, the man looks at to you. He is looking straight in your eyes. Concentrate yourself on what you see and how you feel.

\section{References}

Barron, B.A., van Loon, G.R., 1989. Role of sympathoadrenomedullary system in cardiovascular response to stress in rats. Journal of the autonomic nervous system $28,179-187$.

Davey, G.C.L., 1994. Self-reported fears to common indigenous animals in an adult UK population: the role of disgust sensitivity. British Journal of Psychology 85, 541-544.

de Jong, P.J., Merckelbach, H., 1998. Blood-injection-injury phobia and fear of spiders: domain specific individual differences in disgust sensitivity. Personality and Individual Differences 24, 153-158.

de Jong, P.J., Peters, M.L., Vanderhallen, I., 2002. Disgust and disgust sensitivity in spider phobia: facial EMG in response to spider and oral disgust imagery. Journal of Anxiety Disorders 16, 477-493.

Fessler, D., Haley, K., 2006. Guarding the perimeter: the outside-inside dichotomy of disgust and bodily experience. Cognition and Emotion 20, 3-19.

Fridlund, A.J., Cacioppo, J.T., 1986. Guidelines for human electromyographic research. Psychophysiology 23, 567-598.

Guyton, A.C., Hall, J.E., 2006. Textbook of medical physiology, 11th ed. Elsevier Saunders, Philadelphia.

Haidt, J., McCauley, C., Rozin, P., 1994. Individual differences in sensitivity to disgust: a scale sampling seven domains of disgust elicitors. Personality and Individual Differences 16, 701-713.

Hornby, P.J., 2001. Central neurocircuitry associated with emesis. The American Journal of Medicine 111, 106S-112S.

Kleinknecht, R.A., Kleinknecht, E.E., Sawchuk, C.N., Lee, T.C., Lohr, J., 1999. The medical fear survey: psychometric properties. The Behavior Therapist 22, 109119.

Kleinknecht, R.A., Thorndike, R.M., Walls, M.M., 1996. Factorial dimensions and correlates of blood, injury, injection and related medical fears: crossvalidation of the medical fear survey. Behaviour Research and Therapy 34, 323-331.

Kline, K.P., Ginsburg, G.P., Johnston, J.R., 1998. T-wave amplitude: relationships to phasic RSA and heart period changes. International Journal of Psychophysiology 29, 291-301.

Lang, P.J., 1979. A bio-informational theory of emotional imagery. Psychophysiology $16,495-512$

Levenson, R.W., 1992. Autonomic nervous system differences among emotions. Psychological Science 3, 23-27.

Lumley, M.A., Melamed, B.G., 1992. Blood phobics and nonphobics: psychological differences and affect during exposure. Behaviour Research and Therapy 30 425-434.

Marks, I.M., Mathews, A.M., 1979. Brief standard self-rating for phobic patients. Behaviour Research and Therapy 17, 263-267.

McDougall, S., Widdop, R., Lawrence, A., 2005. Central autonomic integration of psychological stressors: focus on cardiovascular modulation. Autonomic Neuroscience $123,1-11$.

Merckelbach, H., de Jong, P.J., Arntz, A., Schouten, E., 1993. The role of evaluative learning and disgust sensitivity in the etiology and treatment of spider phobia. Advances in Behaviour Research and Therapy 15, 243-255.

Merckelbach, H., Muris, P., de Jong, P.J., de Jongh, A., 1999. Disgust sensitivity, blood-injection-injury fear, and dental anxiety. Clinical Psychology and Psychotherapy 6, 279-285.

Mulkens, S.A.N., de Jong, P.J., Merckelbach, H., 1996. Disgust and spider phobia. Journal of Abnormal Psychology 105, 464-468.

Nederkoorn, C., Smulders, F.T.Y., Jansen, A., 1999. Recording of swallowing events using electromyography as a non-invasive measurement of salivation. Appetite 33, 361-369.

Norris, M.B., Noble, A.C., Pangborn, R.M., 1984. Human saliva and taste responses to acids varying in anions, titratable acidity, and pH. Physiology and Behavior 32, 237-244.

Olatunji, B.O., McKay, D., 2007. Disgust and psychiatric illness: have we remembered? British Journal of Psychiatry 190, 457-459.

Olatunji, B.O., Sawchuk, C.N., de Jong, P.J., Lohr, J.M., 2006. The structural relation between disgust sensitivity and blood-injection-injury fears: a cross-cultural comparison of US and Dutch data. Journal of Behavior Therapy and Experimental Psychiatry 37, 16-29.

Olatunji, B.O., Williams, N.L., Tolin, D.F., Sawchuk, C.N., Abramowitz, J.S., Lohr, J.M. Elwood, L., 2007. The disgust scale: item analysis, factor structure, and suggestions for refinement. Psychological Assessment 19, 281-297.

Öst, L.-G., Sterner, U., Lindahl, I.-L., 1984. Physiological responses in blood phobics. Behaviour Research and Therapy 22, 109-117. 
van Overveld, W.J.M., de Jong, P.J., Peters, M.L., Cavanagh, K., Davey, G.C.L., 2006 Disgust propensity and disgust sensitivity: separate constructs that are differentially related to specific fears. Personality and Individual Differences 41 $1241-1252$.

Page, A.C., 1994. Blood-injury phobia. Clinical Psychology Review 14, 443-461.

Page, A.C., 2003. The role of faintness elicited by blood and injection stimuli. Journa of Anxiety Disorders 17, 45-58.

Palomba, D., Sarlo, M., Angrilli, A., Mini, A., Stegagno, L., 2000. Cardiac responses associated with affective processing of unpleasant film stimuli. International Journal of Psychophysiology 36, 45-57.

Power, M., Dalgleish, T., 1997. Cognition and Emotion: From Order to Disorder. Psychology Press, Hove.

Prkachin, K.M., Williams-Avery, R.M., Zwaal, C., Mills, D.E., 1999. Cardiovascular changes during induced emotion: an application of Lang's theory of emotional imagery. Journal of Psychosomatic Research 47, 255-267.

Proctor, G.B., Carpenter, G.H., 2007. Regulation of salivary gland function by autonomic nerves. Autonomic Neuroscience: Basis and Clinical 133, 3-18.

Rau, H., 1991. Responses of the T-wave amplitude as a function of active and passive tasks and beta-adrenergic blockade. Psychophysiology 28, 231-239.

Ritz, T. Wilhelm, F.H Gerlach, A.L. Kullowatz, A., Roth, W.T., 2005. End-tidal pCO in blood phobics during viewing of emotion- and disease-related films. Psychosomatic Medicine 67, 661-668.

Rohrmann, S., Hopp, H., 2008. Cardiovascular indicators of disgust. Internationa Journal of Psychophysiology 68, 201-208.

Rozin, P., Fallon, A., 1987. A perspective on disgust. Psychological Review 94, 23-41.

Rozin, P., Fallon, A.E., Mandell, R., 1984. Family resemblance in attitudes to food. Developmental Psychology 20, 309-314.

Rozin, P., Haidt, J., McCauley, C.R., 1999a. Disgust: the body and soul emotion. In: Dalgleish, T., Power, M. (Eds.), Handbook of Cognition and Emotion. John Wiley \& Sons Ltd., New York.

Rozin, P., Haidt, J., McCauley, C., Dunlop, L., Ashmore, M., 1999b. Individual differences in disgust sensitivity: comparisons and evaluations of paper- and-pencil versus behavioral measures. Journal of Research in Personality 33, 330-351.

Rozin, P., Nemeroff, C., Horowitz, M., Gordon, B., Voet, W., 1995. The borders of the self: contamination sensitivity and potency of the body apertures and other body parts. Journal of Research in Personality 29, 318-340.

Sarlo, M., Palomba, D., Angrilli, A., Stegagno, L., 2002. Blood phobia and spider phobia: two specific phobias with different autonomic cardiac modulations. Biological Psychology 60, 91-108.

Sawchuk, C.N., Lohr, J.M., Tolin, D.F., Lee, T.C., Kleinknecht, R.A., 2000. Disgust sensitivity and contamination fears in spider and blood-injection-injury phobias. Behaviour Research and Therapy 38, 753-762.

Shapiro, D., Jamner, L.D., Lane, J.D., Light, K.C., Mytrek, M., Sawada, Y., Steptoe, A., 1996. Blood pressure publication guidelines. Psychophysiology 33, 1-12.

Task Force of the European Society of Cardiology and the North American Society of Pacing and Electrophysiology (1996). Heart rate variability: standards of measurement, physiological interpretation and clinical use. Circulation, 93, 1043-65.

Tolin, D.F., Lohr, J.M., Sawchuk, C.N., Lee, T.C., 1997. Disgust and disgust sensitivity in blood-injection-injury and spider phobia. Behaviour Research and Therapy 35, 949-953.

Vögele, C., Coles, J., Wardle, J., Steptoe, A., 2003. Psychophysiologic effects of applied tension on the emotional fainting response to blood and injury. Behaviour Research and Therapy 41, 139-155.

Vrana, S.R., 1993. The psychophysiology of disgust: differentiating negative emotional contexts with facial EMG. Psychophysiology 30, 279-286.

Wenzel, A., Holt, S.J., 2003. Validation of the multidimensional blood-injury phobia inventory: evidence for a unitary construct. Journal of Psychopathology and Behavioral Assessment 25, 203-211.

White, K.S., Sher, K.J., 1977. Saliva: a review and experimental investigation of major techniques. Psychophysiology 14, 203-212.

Wolpe, L., Lang, P.J., 1964. A fear survey schedule for use in behaviour therapy. Behaviour Research and Therapy 2, 27-30. 